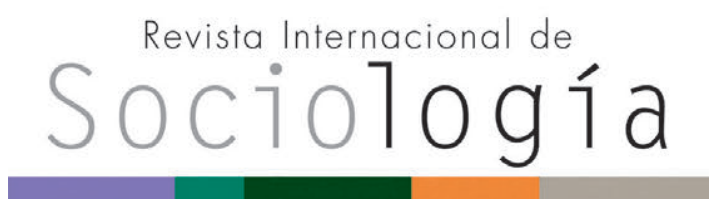

Revista Internacional de Sociología RIS

vol. 75 (1), e054, enero-marzo, 2017, ISSN-L:0034-9712

doi: http://dx.doi.org/10.3989/ris.2017.75.1.15.11

\section{LOS LISTADOS DE CIUDADES GLOBALES \\ Desde la práctica investigadora a su utilización como argumento en la planificación urbana neoliberal}

\author{
Cándida Gago García \\ Universidad Complutense de Madrid \\ cgago@ucm.es
}

ORCID iD: http://orcid.org/0000-0003-2315-7943

\author{
JuAn Córdoba Ordóñez \\ Universidad Complutense de Madrid \\ jcordoba@ucm.es \\ ORCID iD: http://orcid.org/0000-0002-4044-690X
}

\author{
Roberto Díez Pisonero \\ Universidad Complutense de Madrid \\ rdpisonero@ghis.ucm.es \\ ORCID iD: http://orcid.org/0000-0002-7817-628X
}

Cómo citar este artículo / Citation: Gago García, C., J. Córdoba Ordóñez y R. Díez Pisonero. 2017. "Los listados de ciudades globales. Desde la práctica investigadora a su utilización como argumento en la planificación urbana neoliberal". Revista Internacional de Sociología 75 (1): e054. doi: http://dx.doi.org/10.3989/ris.2017.75.1.15.11

\section{Resumen}

El trabajo constituye una reflexión teórica sobre la metodología empleada y el significado otorgado a los listados o clasificaciones de ciudades mundiales. Existe una dilatada literatura académica, ligada al papel que tienen algunas ciudades en procesos territoriales globales, ligada al concepto de ciudad mundial. A esta producción se añaden contribuciones del mundo de la publicidad, la consultoría y los medios de comunicación. Recientemente se han incluido en todos ellos indicadores que reflejan el importante papel económico que adquieren los servicios culturales. Sin embargo, en un contexto de implantación de políticas neoliberales, los ránquines están siendo utilizados, con una narrativa que enfatiza el puesto que ocupa la ciudad, como forma de promoción urbana; al tiempo que la búsqueda y adquisición de un determinado puesto o rango favorece tales prácticas. Este hecho, que consideramos una utilización ideológica de los ránquines, justifica una necesaria reflexión que ahonde en su significado.

\section{Palabras Clave}

Globalización; Listados urbanos globales; Políticas urbanas neoliberales; Servicios culturales; Sistema mundial de ciudades.

\section{GLOBAL CITIES RANKINGS A research agenda or a neoliberal urban planning tool?}

Copyright: (C) 2017 CSIC. Este es un artículo de acceso abierto distribuido bajo los términos de la licencia Creative Commons Attribution (CC BY) España 3.0.

Recibido: 28/01/2015. Aceptado: 18/05/2016. Publicado on line: 07/03/2017

\begin{abstract}
This paper contains a theoretical reflection about the methodology and meaning given to the global city rankings. There is a very large academic production about the role that some cities have in global territorial processes, which has been related to the concept of global city. Many recent contributions from the mass media, advertising and consulting services must be considered also in the analysis. All of them have included new indicators in order to show the main role that cultural services have acquired in the urban economy. Also the city rankings are being used as a tool in neoliberal policies. These policies stress the position that cities have in the rankings, which are used in practices of city-branding and to justify the neoliberal decisions that are being taken. In fact, we think that rankings are used inappropriately and that it is necessary a deep and new reflection about them.
\end{abstract}

\section{KEYWORDS}

Cultural Services; Global Cities Rankings; Globalisation; Neoliberal Urban Policies; World Cities System. 


\section{INTRODUCCIÓN}

La trayectoria en la formulación de jerarquías urbanas en la escala mundial, en donde se estudia cómo diferentes ciudades desempeñan funciones de orden planetario, tiene una amplia trayectoria en Geografía, Sociología y ciencias afines. Desde los planteamientos pioneros de Geddes (1915), retomados y puestos en valor por Hall (1966), hasta nuestros días se han sucedido innumerables intentos por definir lo que se entiende por ciudad mundial o global. Entre estas pueden destacarse las aportaciones de Hymer (1972), Cohen (1981), Friedmann (1986), Castells (1989), Sassen (1991; 2001), Jonhson (1994), Smith y Timberlake (1995), hasta llegar a las del Globalization and World City Research Group (GaWC: Beaverstock et al. 1999; Taylor 2001 y 2004; Derudder y Taylor 2005; Taylor et al. 2013).

Casi todas las aproximaciones formulan propuestas donde se visibiliza un archipiélago mundial de ciudades ordenado según la importancia de estas, en algunos casos muy jerarquizado y que, desde un punto de vista geográfico, resulta relevante a la hora de mostrar qué ciudades son los nodos principales y cuáles son los roles que desempeñan. Los resultados y el debate abierto trascendieron más allá de la determinación del puesto ocupado por una ciudad para formular modelos sobre la organización territorial mundial, a nuestro juicio, muy influyentes y sugestivos. Sirva con citar los ejemplos de "Systeme Monde" (Dollfus 1990) y de "hinterworld", acuñado por el GaWC y cuyo objeto es describir el patrón mundial de conexiones entre ciudades en condiciones de globalización (Taylor 2001).

Entre los rasgos más destacados de las distintas propuestas cabe señalar la consolidación del concepto de ciudad global (Sassen 1991), el papel que juegan las ciudades en una estructura de malla o de red (Friedman 1986; Castells 1989; Taylor 2004; Taylor et al. 2013), la contextualización de la ciudad en el marco geográfico donde se localiza -de donde se deriva una división territorial de funciones en la escala mundo en relación con el rango y los roles (Dollfus 1990)$\mathrm{y}$, por último, la consideración de que rango y función no son estáticos sino que pueden variar, al tratarse de un proceso histórico (Brenner 1998). Las diferencias en estos planteamientos abrieron también una amplia controversia epistemológica que llega hasta nuestros días; por ejemplo, en la posible diferencia entre los conceptos de ciudad mundial y ciudad global, matiz que parece superado (Taylor 2004).

En cualquier caso, cabe afirmar que las diferentes formulaciones conceptuales y metodológicas que se vienen realizando durante la trayectoria señalada deben estar revisándose continuamente. Ello se debe fundamentalmente a la proliferación en las dos últimas décadas de nuevas propuestas que inundan este campo de estudio, provenientes esencialmente del mundo de la consultoría y los medios de comunicación, cuyo objetivo es, en gran parte de las ocasiones, proporcionar un ranquin o jerarquía, después ampliamente difundido en las redes de comunicación, sin realizar una reflexión más allá del dato en sí y contextualizar los resultados. Además se observa un cambio importante en la naturaleza de los indicadores empleados, incluyéndose otros muchos, especialmente en relación con el alto significado que han adquirido las actividades y servicios creativos, culturales y de ocio-consumo en las ciudades. Todo ello viene a señalar que los conceptos de ciudad mundial y de rango urbano se han hecho especialmente populares, siendo ampliamente formulados por consultoras y organismos de investigación o desarrollo y adoptados como una herramienta de planificación urbana.

- En relación con estas ideas cabe decir que se ha asistido a un progresivo incremento del peso que adquieren los servicios en la dinámica urbana, de donde se deriva que las actividades industriales han perdido peso relativo en relación con el conjunto total de actividades, al menos en los países occidentales. En este sentido, los análisis han empezado a incorporar variables en relación con la innovación y la cultura de modo que resulten más significativos; sobre todo a través de los servicios creativos, culturales y de ocio-recreación. En principio consideramos que su estudio enriquece el conocimiento de la organización y vertebración del territorio en la escala planetaria. Castells (1989) señaló, ya hace tiempo, que la ciudad no es solo una ubicación característica, sino parte constituyente de los procesos de consumo colectivo inherentes al capitalismo. A estas consideraciones hay que añadir que el consumo en las ciudades adquiere tintes globales y uniformizantes (Ritzer 1993) y que este no solo se restringe a los residentes sino que se hace extensible a los visitantes y turistas que acuden a ellas como una práctica más de la modernidad (Urry 2002).

- Además, desde hace unos años se observa una prolífica producción de clasificaciones ajenas a la agenda de la geografía y la sociología. Estas están en relación con temas de interés para la economía, el urbanismo o el ambientalismo mientras que otras son simples reclamos a la curiosidad y aparecen recogidas en revistas y periódicos; por ejemplo, Forbes presenta "las mejores y peores ciudades del mundo" y "las mejores ciudades para solteros"; The Telegrah, destina un artículo a "las mejores ciudades para vivir"; o Travel and Leisure, dedicada temáticamente al turismo, reserva también en sus premios World Best Awards una categoría específica para "las mejores ciudades" (Top 10 Cities). Esta ten- 
dencia también se observa en España y así encontramos un sinnúmero de páginas escritas sobre ciudades de España y del mundo que recogen clasificaciones o listados $(A B C$, "las diez mejores ciudades para...estudiar, trabajar, hacer negocios, vivir, visitar, divertirse...; El País, "La ciudad número 1"; 20 Minutos, "Las 15 Mejores Ciudades de Latinoamérica para vivir"), constituyendo todo ello una lista interminable.

- Cabe señalar el interés que han suscitado los listados ordenados de ciudades en las oficinas municipales de promoción o de estudios estratégicos, en las consultoras y asesorías de negocios y en las empresas inmobiliarias. Se observa cómo algunos de ellos son instrumentalizados por agentes políticos y sociales a favor de un discurso de tinte neoliberal donde el interés fundamental es que una determinada ciudad ostente un rango alto. Sobre la base de este hecho, se justifican e implementan acciones cuya finalidad es mejorar la posición internacional de la ciudad, aspecto que se espera que granjeará inversiones y la posibilidad de mantener o mejorar su estatus.

Teniendo en cuenta estas evidencias, las siguientes líneas pretenden valorar en qué medida el concepto de "ciudad global" está siendo empleado como una herramienta de naturaleza neoliberal para la planificación urbana. Como se verá, a nuestro entender se trata de un ejemplo de práctica similar a aquellas definidas por Ong (2006), asociadas con intercambios de información e ideas que migran de un lado a otro a través de múltiples ligazones que se establecen actualmente entre lo local y lo global. Ellas constituyen flujos de técnicas y racionalidades de gobernanza que se incrustan en los lugares, y cuyo objetivo es lograr condiciones territoriales que favorezcan el intercambio económico y la economía de mercado. En esta misma línea argumental debe tenerse en cuenta la propuesta de Brenner, Peck y Theodore (2010) quienes afirman que lo local juega un papel esencial como promotor de las dinámicas neoliberales, ya que sus discursos y acciones tienen el potencial de incluirse y filtrarse como práctica prioritaria en los circuitos locales y translocales. Todos estos aspectos aparecen teorizados en la ciencia social dentro del concepto genérico de "fast policy" en referencia a distintas ideas políticas; en especial, aquellas que funcionan y que son capaces de encontrar rápidamente eco mundial y una relevancia transnacional favorecidas por la interconexión que proporcionan las tecnologías de la información y la comunicación (Peck y Theodore 2015).

Los contenidos de este artículo se estructuran en tres apartados, además de la presente introducción. A continuación se pretende analizar en qué medida el término ciudad global y la propuesta de clasifica- ciones ordenadas -ranking, utilizando un término prestado del inglés-, de muy distinta naturaleza, han sido adoptados como objetos de interés por consultores y otros agentes que intervienen activamente en las políticas de las ciudades como forma de medir la globalidad; para ello se sigue, en la mayor parte de las ocasiones, una racionalidad de maximización y eficacia, lo que hace que metodologías e indicadores estén constantemente implementándose.

Además, el hecho de alcanzar una posición alta en un listado llega ser un objetivo para determinados agentes de la política urbana local, aspecto que se valorará en el apartado tercero. En este sentido, la obtención de una buena posición por parte de una ciudad se ha convertido, en sí mismo, en un objetivo de las políticas urbanas, donde la ciudad se concibe como una empresa que compite por atraer inversiones y flujos. Consideramos que se trata de una instrumentalización política, incluso ideológica, de los listados sobre ciudades, lo que ha vaciado de contenido geográfico el término "ciudad global", favorecido en cierta medida por el tinte economicista que adquirieron algunas investigaciones. La exposición finaliza con la puesta en valor de una serie de reflexiones, derivadas de la ciencia social, que debieran ser el fundamento teórico que continúe alimentando la formulación de jerarquías urbanas.

\section{Naturaleza, OBJEtivos Y Componentes DE LOS LISTADOS DE CIUDADES GLOBALES}

Las relaciones entre globalización y ciudades son, en el momento presente, un hecho geográficamente constatado y, como se ha subrayado, su estudio ha revertido en una de las mayores producciones académicas dentro de la geografía y la sociología. Ello ha proporcionado un importante cuerpo teórico y de discusión acerca de los parámetros más adecuados para definir una ciudad mundial, utilizando, además, diferentes aproximaciones metodológicas (Derudder 2006). Taylor (2004) plantea una disyuntiva esencial a la hora de identificar el grupo de ciudades de orden global. Según él, debe diferenciarse entre las propuestas que se basan en la valoración de la concentración de recursos en las ciudades (ej.: empresas multinacionales asentadas), y aquellas donde lo esencial es la presencia de una red interrelacionada y trasnacional de flujos. Para este segundo planteamiento la centralidad es determinante, siendo el elemento esencial para la consecución de poder económico, político, etc. (Sassen 1994; Castells 1989; Allen 1999). Taylor (2004) también sostiene que respecto a estos planteamientos se puede adquirir, desde un punto de vista metodológico, una posición ecléctica; ya que el debate ha exagerado las diferencias, puesto que los resultados se asemejan.

Asimismo, la producción científica ha utilizado una variedad importante de indicadores para deter- 
minar qué ciudades pueden considerarse globales y cuál es su rol en el archipiélago mundial. La Tabla 1 , adaptada de Derudder (2006), sintetiza las principales aproximaciones, tanto desde el punto de vista de la naturaleza de los datos como si el enfoque está basado en la concentración de atributos o en el estudio de los flujos.

No faltan voces disidentes que señalan la imposibilidad de definir e identificar totalmente a las ciudades globales, acusando a estos enfoques de reduccionistas y de carencia de relevancia, entre ellas la teoría de la no-representación (Thrift 2000; 2007); según esta, los nodos urbanos son más que centros de poder "conmutadores", lugares donde se entrecruzan tiempos, espacios, experiencias, a los que no es posible poner límites ni fronteras (Smith 2003). En esta misma línea Marcuse y Kempen (2000) señalan que la globalización es un proceso que se manifiesta en diferente forma e intensidad y por tanto, no deben ser consideradas en el análisis solo las ciudades globales sino también lo que se ha denominado ciudades globalizantes o en proceso de globalización. Otras críticas inciden en la desconexión entre la identificación de las ciudades globales y la elaboración de un marco geopolítico interpretativo adecuado que explique los procesos políticos y de gobernanza que configuran las más importantes ciudades del mundo y que dé respuesta a por qué "no hay un único modelo de ciudad global, sino diferentes patrones" (Olds y Yeung 2004).

Paralelamente a este interés académico, han irrumpido, sobre todo en los últimos años, numerosos informes que con diferentes finalidades y temáticas presentan categorizaciones de ciudades ${ }^{1}$, tratándose de un fenómeno que se afianza en el círculo de la consultoría, los agentes inmobiliarios, el marketing urbano, la publicidad y los touroperadores. Además debe insistirse en la intensa cobertura que les dedican los medios de comunicación.

En las Tablas 2 y 3 aparecen recogidos comparativamente diez de los listados de ciudades mundiales más importantes ${ }^{2}$. Cabe decir que todos ellos destacan por su actualidad ya que el más antiguo, GaWC, tiene una antigüedad inferior a 6 años; además solo tres de los diez seleccionados tienen relación directa con el mundo académico y uno de estos ha sido realizado en colaboración con un medio de comunicación (Revista Atlantis). Gran parte de los estudios son realizados por consultoras, aunque en su formulación también pueden intervenir entes públicos o privados con un fin político y/o estratégico (The Mori Memorial Foundation) o con un propósito informativo (Revistas: The Economist y Atlantis). Conviene en este punto anticipar que debido a la diversidad de variables y metodologías utilizadas, las clasificaciones no son comparables entre sí pero en muchas ocasiones ello sí se hace, como en los trabajos de Taylor (2004) o Skorska y Kloosterman (2012). En ambos casos se insiste en la dificultad de la comparación y que precisamente esta se realiza para poner de manifiesto la variabilidad de resultados y que los mismos deben ser interpretados dentro de los contextos y utilidad para los que han sido elaborados.

Los ejemplos seleccionados en estas líneas muestran un afán notable por fijar indicadores precisos para determinar que ciudades son las importantes, en relación, con aquellas temáticas que interesa investigar. Ello puede determinar el número de indicadores y dimensiones que se incorporan en el análisis, que oscila entre un solo indicador (GaWC) hasta los 162 que utiliza el Global Power City Index ("Actor Specific Ranking"). Posteriormente, de los distintos

Tabla 1.

Aproximaciones empíricas al sistema mundial de ciudades. Ejemplos seleccionados

\begin{tabular}{|c|c|c|c|c|c|}
\hline & Demografía & \multicolumn{2}{|c|}{ Organización de las empresas } & \multicolumn{2}{|c|}{ Infraestructura (flujos) } \\
\hline $\begin{array}{c}\text { Agentes } \\
\text { clave }\end{array}$ & $\begin{array}{c}\text { Población } \\
\text { Inmigración }\end{array}$ & $\begin{array}{c}\text { Firmas de servicios } \\
\text { avanzados a la } \\
\text { producción }\end{array}$ & $\begin{array}{c}\text { Empresas } \\
\text { multinacionales }\end{array}$ & $\begin{array}{c}\text { Telecomunicaciones } \\
\left({ }^{*}\right)\end{array}$ & Transporte físico \\
\hline \multirow{2}{*}{ Ejemplos } & $\begin{array}{c}\text { Bretagnolle, Pumain } \\
\text { y Vacchiani (2007) }\end{array}$ & Taylor (2002) & $\begin{array}{c}\text { Alderson y Beckfield } \\
(2004)\end{array}$ & Townsend (2001) & $\begin{array}{c}\text { Smith y Timberlake } \\
(2002)\end{array}$ \\
\cline { 2 - 5 } & $\begin{array}{c}\text { Benton- Short et al. } \\
(2005)\end{array}$ & $\begin{array}{c}\text { Derudder y Taylor } \\
(2005)\end{array}$ & $\begin{array}{c}\text { Rozenblat y Pumain } \\
(2005)\end{array}$ & Gago (2002) \\
\hline Indicadores & $\begin{array}{c}\text { Tamaño Demográfico } \\
\text { Flujos de inmigrantes }\end{array}$ & $\begin{array}{c}\text { Flujos de informa- } \\
\text { ción y conocimiento } \\
\text { entre ciudades }\end{array}$ & $\begin{array}{c}\text { Número de sedes de em- } \\
\text { presas multinacionales y } \\
\text { sus relaciones intra-firma }\end{array}$ & $\begin{array}{c}\text { Red de banda ancha de } \\
\text { Internet entre ciudades }\end{array}$ & $\begin{array}{c}\text { Pasajeros aéreos } \\
\text { Conectividad aero- } \\
\text { portuaria }\end{array}$ \\
\hline
\end{tabular}

Fuente: Adaptado de Derudder (2006); se ha añadido la columna "Demografía". 
indicadores se derivan índices agregados donde temáticas, dimensiones y variables se agregan para obtener un resultado que suele ser una expresión numérica. En las Tablas 3 y 4 se puede apreciar, precisamente, la naturaleza variada de los diez trabajos seleccionados tanto por su temática, el número de indicadores y de ciudades que se incluyen, las dimensiones en que se agrupan los temas, como por las fuentes de información a las que se recurre.

Las formas de cálculo con las que se obtienen los resultados son bastante variadas. Se observa por ejemplo, como se combinan indicadores que, agrupados en diferentes dimensiones, son a su vez ponderados según se consideren más o menos importantes. No se han constatado, al menos en aquellos analizados en este trabajo, procesamientos matemáticos complejos como pueden ser análisis factoriales y clúster. La naturaleza de la información que se utiliza incluye tanto valoraciones cualitativas, otras formuladas por informantes clave, la combinación de aspectos cualitativos y cuantitativos, como datos únicamente cuantitativos. Además todos ellos se pueden adquirir tanto de fuentes externas como por elaboración propia.

Debe insistirse de nuevo en que estas clasificaciones resultan difícilmente comparables entre sí, pues están compuestas de múltiples variables e indicadores donde, a aquellas de temática económica se han sumado otras que inciden en aspectos sobre bienestar, dotación de servicios e infraestructuras, medio ambiente, representación política, gobernanza e implantación de criterios de participación democrática, entre otros. En este sentido, resulta complicado proponer una clasificación de los contenidos temáticos a los que son adscritos los indicadores, porque muchos de estos están interrelacionados (Tabla 5). Por ejemplo algunos trabajos consideran los aspectos de salud conjuntamente con los de carácter medioambiental, mientras que otros los engloban dentro de dimensiones relacionadas con la calidad de vida; al tiempo que la calidad de vida y el medioambiente también pueden considerarse interrelacionados.

Con respecto a los indicadores que incluyen estos trabajos, algunos autores han señalado que la cultura y ciertas actividades relacionadas, como la investigación y el desarrollo del talento, habían aparecido hasta fechas cercanas como un debate menor en el concepto de ciudad mundial (Pratt 2011; Mayor of London 2012). Esto puede resultar paradójico teniendo en cuenta el peso cada vez más importante de las actividades de innovación, culturales y creativas, que se manifiesta tanto desde un punto de vista económico, como en las formas de vida propiamente urbanas. En este sentido, bajo la denominación genérica de servicios culturales y creativos cabe referirse a los servicios a las empresas intensivos en conocimiento (KIBS, knowledge intensive business services), cuya característica fundamental es la alta dotación tecnológica o formación del personal, y a las industrias culturales, cuya producción parte de motivaciones en el campo artístico (artes escénicas y plásticas, edición, audiovisuales) a las que se añaden los sectores del diseño, la moda o la arquitectura, entre otros (Sánchez Moral 2011); precisamente la creatividad y la innovación son los nexos de unión entre ambos grupos de actividades y también la componente básica de su éxito reciente.

En relación con el significado creciente de este conjunto heterogéneo de actividades, solo las industrias KIBS generaron 2.706 billones de dólares del PIB mundial en 2005, al tiempo que el valor de las exportaciones mundiales de bienes y servicios creativos alcanzó los 424 billones de dólares ese mismo año, es decir, un 3,4 \% del comercio internacional (Sánchez Moral, ibíd.). Se puede apuntar, además, que el cambio de modelo productivo obedece a una reinvención de la ciudad dentro del paradigma productivo neoliberal donde las actividades ligadas al conocimiento, al talento, la creatividad y el consumo juegan un papel fundamental en su organización, no solo como un elemento económico, sino también desde el punto de vista de la experiencia de los consumidores (Miles 2012). Otros autores van más allá conceptualizando los núcleos urbanos como los emblemas donde se plasman las prácticas económicas actuales del capitalismo y donde la creatividad y la cultura tienen cada vez mayor protagonismo como actividades de producción y consumo; en este sentido, las ciudades son el marco donde se crea toda una narrativa que sostiene la economía cultural (Amin y Thrift 2007). Para estos últimos el capitalismo se está moviendo en una fase donde la generación de productos culturales es crucial en la estrategia productiva (Scott 2007) y en donde los servicios están impregnados de un modo u otro con características generalmente estéticas y semióticas (Lash y Urry 1994; Molotch 1996). Además, en las sociedades actuales la ciudad en sí misma se ha convertido en un objeto de consumo (Mansvelt 2008).

Todo este debate ha abierto la puerta en las dos últimas décadas a la proposición de nuevas jerarquías urbanas o a que en estas se incluyan otras ciudades cuyo eje de actividad no se encuentra en el sector manufacturero, sino en la producción de ideas y la dotación de servicios intangibles. Este contexto de análisis estresa el papel innovador, cultural y creativo de las ciudades, en donde estos sectores pasan a ser el corazón de la actividad (Currid 2006), creándose economías de escala que favorecen la creatividad, el aprendizaje, el conocimiento, a la vez que se atrae el talento que generará innovaciones. Destacan las ideas de la Escuela de los Ángeles y su formulación del concepto de "Ciudad Celebrity" (Soja y Scott 1986) y aquellas centradas en la economía del conocimiento (Scott 2000 y 2011); una de las propuestas más reconocidas es el denominado "paradigma de las industrias creativas” (Scott 2000; Florida 2002). 
Otros atributos de la ciudad tienen relación con la generación de un ambiente atractivo, vivo o vitalista, repleto de eventos culturales, barrios y escenarios preparados para el ocio y la fiesta, incluyendo también valores como la tolerancia, la multiculturalidad y el ambiente bohemio. Aparecen así indicadores variadísimos para medir estas nuevas dimensiones: Inequality Index, Tolerance Index, Creativity Index, Boheminan Index, Coolness Index (Florida 2002 y 2005; Florida y Tinagli 2004). Algunos de ellos son ampliamente discutidos en cuanto a su contribución a la globalidad de la ciudad y al crecimiento económico (Evans 2009), pero interesa conocer su formulación y su inclusión en las clasificaciones más recientes. Consecuentemente, los servicios culturales y creativos se enarbolan actualmente como un elemento fundamental de competitividad urbana (Méndez y Sánchez 2011); de hecho, autoridades y planificadores confeccionan ex novo narrativas sobre barrios supuestamente "cool" o "vanguardistas" para favorecer la instalación de clases creativas (Mihye 2010).

Estos aspectos han propiciado que la mayor parte de los listados urbanos incluyan hoy día indicadores culturales y creativos, ligados a la sociedad de la información y el conocimiento y también al consumo de actividades culturales y de ocio-recreación como puede verse en aquellos seleccionados en este trabajo (Tablas 4 y 5). Un análisis temático de los indicadores sobre servicios culturales y creativos permite identificar cuatro grandes grupos: (a) medio sociopolítico, (b) educación, investigación e innovación, (c) información e infraestructura de comunicaciones y telecomunicaciones y (d) cultura, ocio y consumo. Dos de estos grupos, medio sociopolítico y cultura, ocio y consumo, guardan, además, una amplia relación con un entendimiento holístico de la actividad cultural, creativa e innovadora, incluyendo variables como la tolerancia, la aceptación de la diferencia, la multiculturalidad, la vitalidad o el carácter bohemio. Con respecto al peso (ponderación) que se otorga a las variables culturales en el resultado final, este depende, en la mayor parte de los casos, de una decisión metodológica determinada en los planteamientos iniciales y en los objetivos. Los criterios de ponderación (Tabla 4) son muy variados, oscilando entre un $36 \%$ aproximadamente (World Libeable Cities) y el 74\% (Global Cities Index Project).

La variedad de metodologías, criterios de selección de indicadores, pesos o ponderaciones dadas a las dimensiones y, lo que se nos antoja primordial, de la cantidad y disparidad de ciudades incluidas en el análisis, hace que los resultados deban ser leídos con cautela. En esta línea, otros autores señalan que estos listados dependen mucho del tipo de objetivo que se pretenda, de ahí su diversidad tanto en los métodos empleados como en los indicadores seleccionados, y que sus características deben ser determinadas en función del objetivo, de la metodología empleada en su formulación y del nivel de difusión de sus resultados. También se indica que los estudios realizados incluyen un número muy variable de ciudades, seleccionadas con criterios dispares, y que las formas de elaborar los resultados incluyen también métodos de ponderación y normalización que a veces resultan discutibles (Giffinger et al. 2010)

En algunos de estos listados cabe sospechar, además, un fin propagandístico tanto por parte de los equipos elaboradores, al demostrarse su capacidad para la realización de estos trabajos, como por parte de las ciudades, ya que a todas ellas interesa la obtención de un puesto privilegiado (King 1995; Yeoh 2005), tal como se verá en el epígrafe siguiente. Con esta misma línea argumental algunas voces señalan el poder y el peligro que tiene la formulación de clasificaciones urbanas. Amin y Thrift (2007) las califican como una industria altamente lucrativa que está, cada vez más, convirtiéndose en la guía en la que se apoyan las decisiones locacionales... "ellas pueden constituir o destrozar una ciudad".

Por lo descrito hasta el momento puede apreciarse que la información sobre la situación económica, social, medioambiental y de calidad de vida de las ciudades en estos estudios no se mide en relación con el contexto inmediato, sino a escala internacional. Igualmente, que las listas de ciudades clasificadas por rango de importancia se han visto implementadas, además, con aquellos indicadores que interesan especialmente para el desarrollo económico, como es el caso de los servicios culturales. En este mismo sentido, la información sobre la situación de las ciudades es vista como un campo de conexiones, intercambios y circulación y formación de ideas, que es transmitida a través de alianzas de informadores, donde participan tanto empresas de consultoría como medios de comunicación y en donde también se ha incorporado el mundo académico. En un intento por explicar cómo se establecen estos juegos de actores, algunos trabajos (McCann 2011) han identificado una amplia infraestructura en red de carácter electrónico o virtual, fácilmente accesible por medio de internet, implementada por la presencia intermitente de esas élites informacionales en diferentes lugares (visitas a ciudades, reuniones de expertos, convenciones, conferencias, seminarios...).

Así, este expertice internacional constituye para distintos autores especializados (Clarke 2012; McCann 2010) la "arena" donde las cuestiones, problemas y demás aspectos urbanos se formulan e identifican conjuntamente con sus soluciones, algunas de las cuales pugnan por imponerse como, por ejemplo, el concepto de ciudad global. En estas redes participan informadores y periodistas, consultores internacionales, miembros de prestigiosos think tanks, abogados y arquitectos, evaluadores, distinguidos académicos, junto con políticos y planificadores urbanos que en muchos casos consideran este tipo de actuaciones 
un negocio (Larner y Laurie 2010; Peck y Theodore 2010). Se trata además de nociones que se expanden de forma viral, como es el caso de la idea de ciudad creativa, cuyo éxito se debe para algunos, no tanto en la virtud de haber sabido captar la esencia de las dinámicas urbanas contemporáneas, sino en la necesidad reciente de solventar las crisis económicas mediante actuaciones eficaces y muy rápidas ligadas a modalidades en empresarialismo urbano (Peck 2009).
En este sentido, y tal como se verá a continuación, el concepto de ciudad global y ranking urbano está siendo utilizado como herramienta fundamental para desarrollar cierto tipo de políticas, entendidas por algunos analistas como formas de experimentación regulatoria que favorecen los procesos económicos neoliberales que se desarrollan en las ciudades (Clarke 2012; Brenner, Peck y Theodore 2010).

Tabla 2.

Ciudades en los puestos superiores. Listados urbanos seleccionados

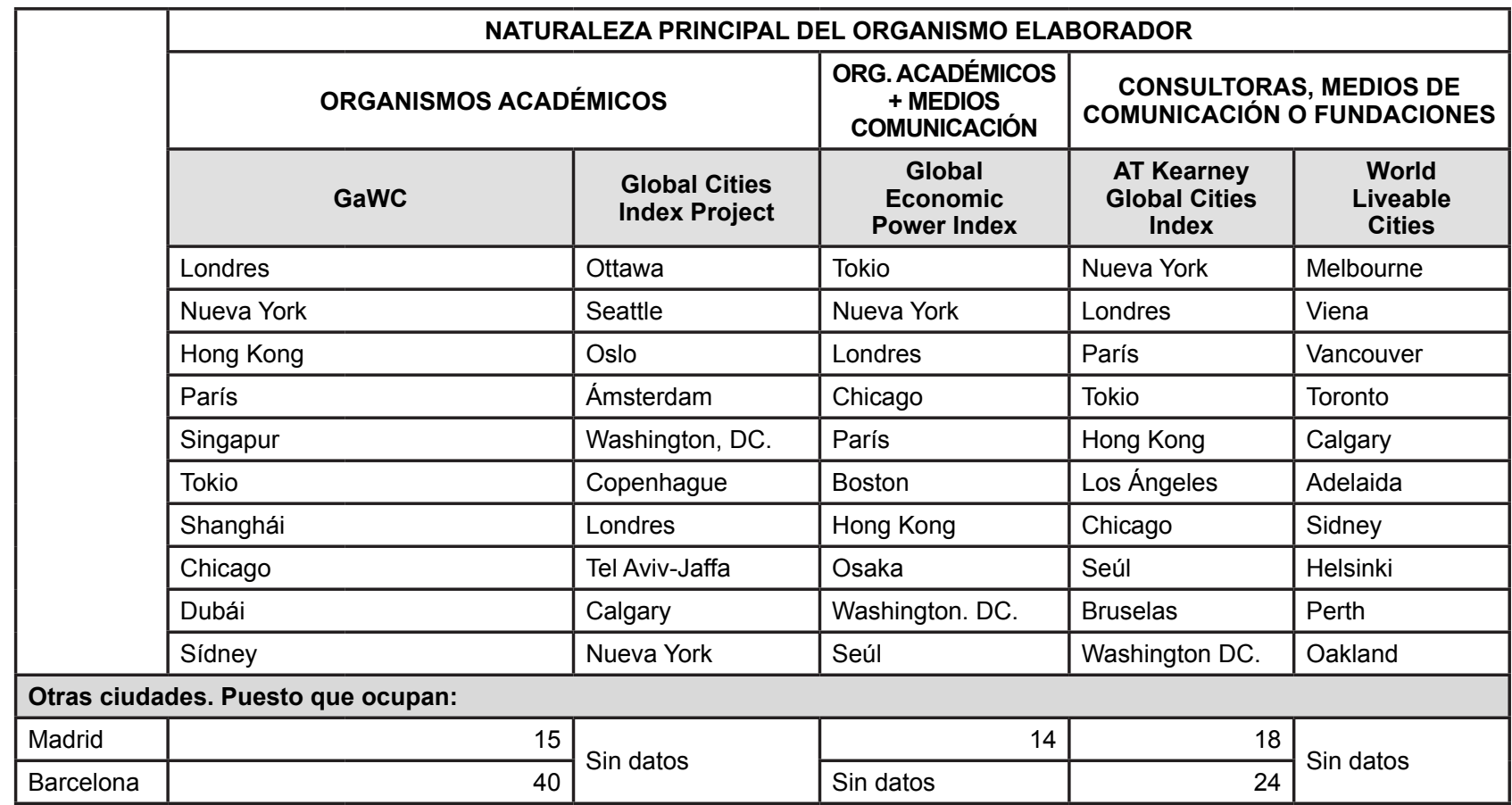

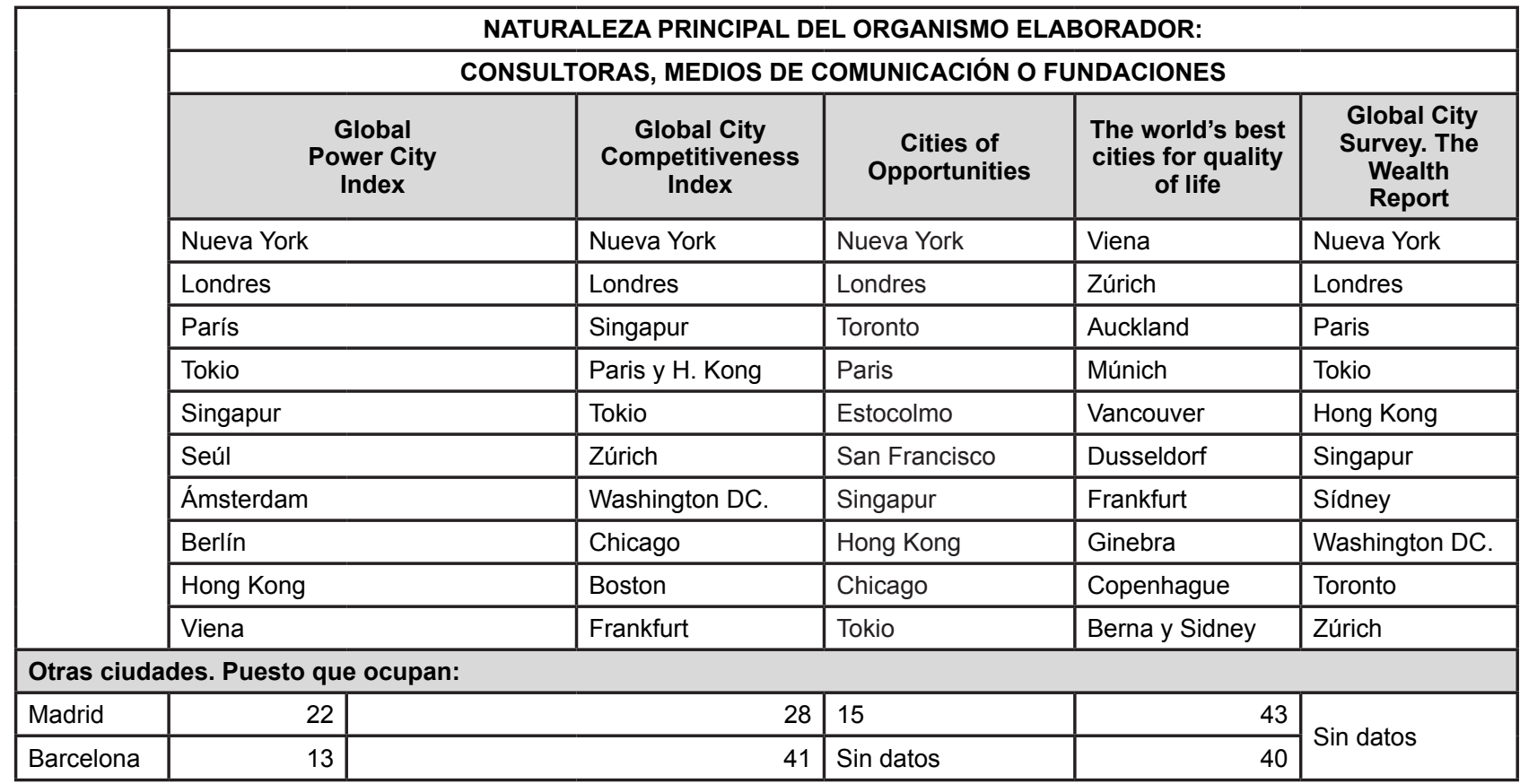

Fuente: Publicaciones de los distintos trabajos (ver Tabla 3). Elaboración propia. 


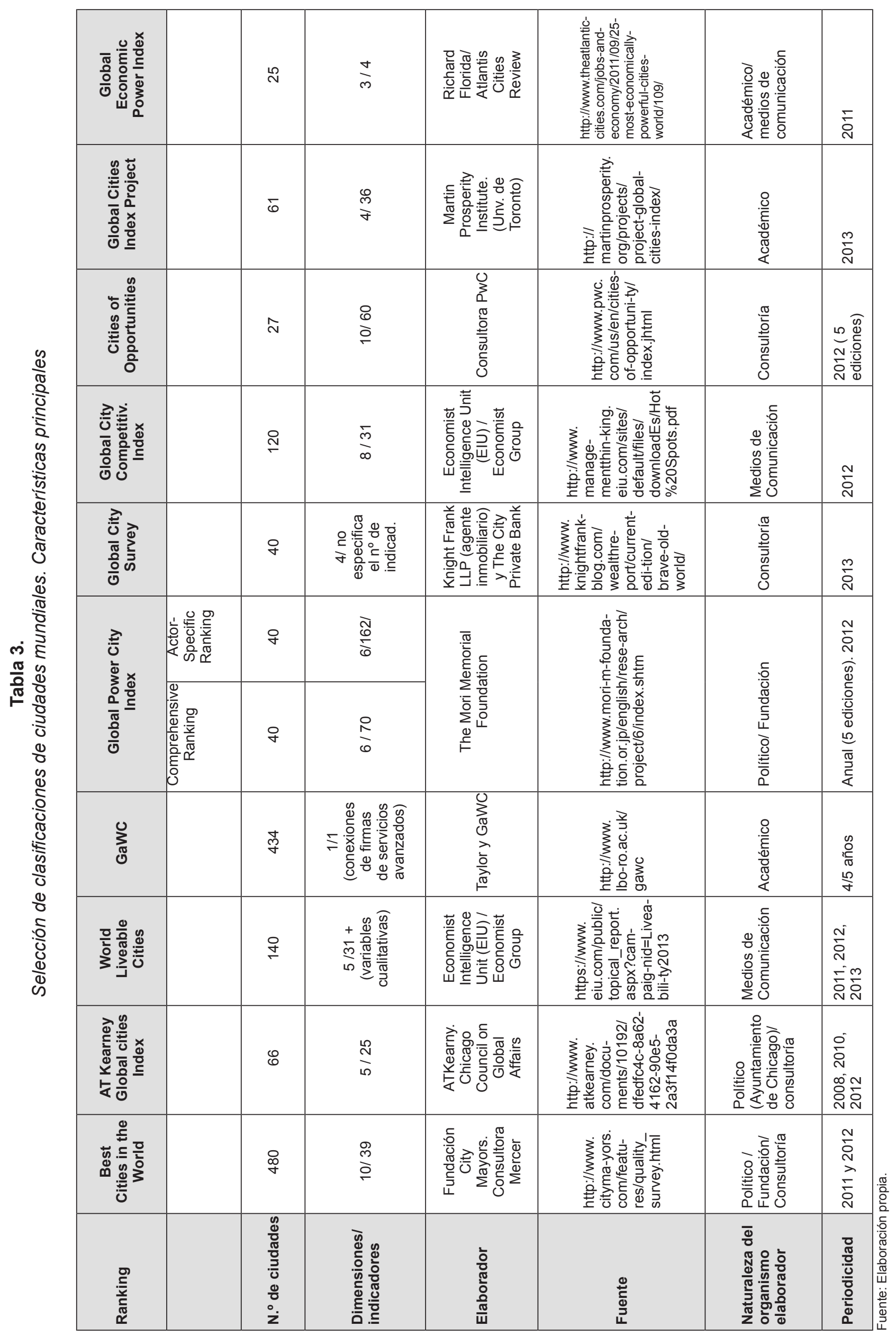




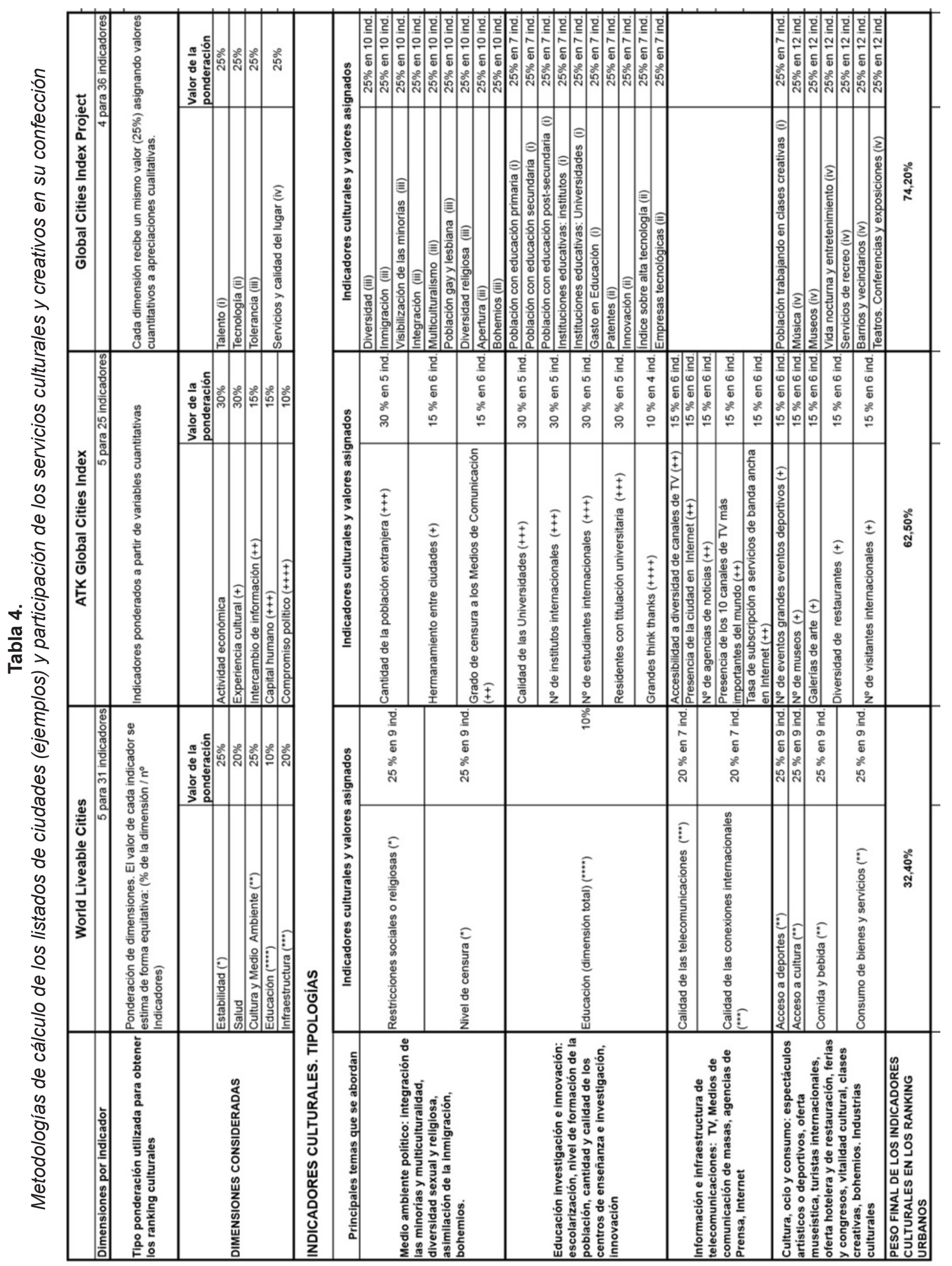


Tabla 5.

Grupos temáticos utilizados en la realización de listados de ciudades*

\begin{abstract}
Economía (Actividad económica y medio ambiente de negocios). Indicadores macroeconómicos (PIB, valor del mercado de capitales, volumen financiero, crecimiento del PIB y de la IED), actividad financiera y de capitales, presencia de multinacionales, integración económica multinacional, servicios para las empresas, regulaciones favorables para los negocios, productividad y costes de producción, gestión de riesgos económicos. Renta personal y poder adquisitivo de la población.
\end{abstract}

Servicios de información e infraestructura de telecomunicaciones: TV, Medios de comunicación, prensa, Internet. Infraestructura de comunicaciones.

Servicios públicos y vivienda: infraestructuras básicas (a excepción de las telecomunicaciones), construcción, vivienda, transporte público y privado, puertos, aeropuertos, energía.

Educación, investigación e innovación: escolarización, nivel de formación, calidad de la enseñanza e investigación, innovación.

Vida cultural y oferta de ocio y consumo: espectáculos artísticos o deportivos, oferta museística, turistas internacionales, diversidad y calidad de la oferta hotelera y de restauración, hermanamiento entre ciudades, ferias y congresos, vitalidad cultural, clases creativas, "bohemios".

Medio ambiente social y natural: indicadores medioambientales, indicadores de bienestar social y condiciones de trabajo. Sanidad y salud de la población.

Ambiente democrático y apertura política: criminalidad, conflictos y guerras, seguridad, buen gobierno o gobernanza, corrupción, estabilidad política, valores democráticos (libertad política, censura, respeto a los Derechos Humanos, integración de las minorías y multiculturalidad, exención y facilidad para obtener visados, diversidad sexual y religiosa, asimilación de la inmigración), bohemios.

Visibilidad o representatividad política: presencia de embajadas y consulados, lobbies, organizaciones internacionales, conferencias políticas celebradas.

* Realizado a partir de las 10 clasificaciones seleccionadas para el análisis. Fuente de cada una: ver Tabla 3. Elaboración propia

\section{LOS LISTADOS DE CIUDADES: EJEMPLOS DE SU USO COMO COMPONENTE DEL DISCURSO NEOLIBERAL}

Este apartado pretende ahondar en cuestiones tales como el para qué y de qué manera se utilizan los listados urbanos, al menos en los últimos tiempos. Se ha señalado que el proceso de terciarización económica y el aumento de las prácticas de consumo forman también parte de un ideario neoliberal que se difunde con la globalización y que tiene su territorio de implantación en las ciudades. Se viene observando cómo las personas, bienes, capitales e ideas no circulan de manera casual por el mundo, sino que siguen un "patrón de atracción que se genera en aquellas ciudades que, dadas sus ventajas económicas, políticas o simbólicas, controlan su magnitud e intensidad" (Sabaté y Tironi 2008). Así, surgen nuevas perspectivas de análisis en los estudios urbanos, al introducir el concepto de competitividad y por consiguiente la valoración de las estrategias que se adoptan. Cabe decir que la competencia entre las ciudades no es un fenómeno específico de finales del siglo XX. Sin embargo, diferentes acontecimientos del último tercio de la centuria pasada como la mundialización de la economía, la revolución de los transportes o la extensión de las áreas de influencia, entre otros, han ampliado la dimensión y la escala de la competitividad urbana que ha acabado por adquirir una extensión global.

Las estrategias de competitividad se basan en la aplicación de planteamientos neoliberales a las políticas y a la planificación, favoreciendo la atracción de actividades productivas, sobre todo de servicios, mediante la reconversión morfológica y de usos del suelo, la adaptación del mercado de trabajo, la creación de un clima institucional favorable y además la elaboración de una imagen o "marca" de ciudad que incida en los rasgos de identidad y distinción frente al resto (Markusen y Shock 2006; Fuentes 2011; Canosa y García 2012).

En este contexto, recabar información sobre los aspectos que permiten a las ciudades ser exitosas ha resultado de alto interés. Consecuentemente, las clasificaciones de ciudades se han convertido en una herramienta muy importante para la planificación estratégica urbana, siendo utilizadas para asesorar sobre las estrategias más adecuadas (Giffinger et al. 2010) ya que proporcionan información considerada altamente relevante. Un aspecto que empieza a remarcarse en la literatura científica es la instrumentalización política de los mismos. Su inicio parece situarse en el cambio desde las políticas de tipo keynesiano hacia otras de corte marcadamente neoliberal, orientadas básicamente hacia una liberalización económica. Con estos planteamientos, las ciudades son obligadas de manera exponencial a competir en la búsqueda de nuevas oportunidades, siendo gestionadas como una empresa (Harvey 1989). Las políticas urbanas adquieren características similares a las de otros sectores privados, compitiendo por inversiones de todo tipo (Tremblay et al. 2008). En este contexto, el término de ciudad global, que había sido introducido en el mundo académico a principios del siglo XX y generalizado en la década de 1960, es redescubierto por economistas y urbanistas, pasando a jugar un papel en la política y la planificación. El proceso es el siguiente: 
- La necesidad de racionalidad en la política debido al contexto socioeconómico hace que ciertas ideas se conviertan en hegemónicas, atribuyéndoseles ser fuente de conocimiento y de verdad. Estas son presentadas por expertos en urbanismo de prestigio internacional, que usan una narrativa persuasiva que incluye los aspectos estratégicos a tratar, adaptados a un contexto territorial específico, con el objeto de convencer a agentes o actores locales, muchos, proclives a escuchar y recibir el mensaje, para que se opte por determinadas prácticas (Rose y Miller 1992; Osborne 2004; McCann 2011).

- A ello se suma que las instituciones de gobierno de las ciudades actúan como empresas en búsqueda de atracción de capitales, de ideas y de ciertos perfiles técnicos y profesionales (Jessop y Sum 2000).

- Para ello, entre otros aspectos, se enfatiza el carácter innovador, creativo y de ocioconsumo de las ciudades y de algunos de sus barrios; así, el patrimonio, las actividades desarrolladas y los servicios que se prestan son utilizados por las autoridades como una estrategia de diseño de marca (Evans 2003 y 2009), donde obtener el calificativo de ciudad global se ha convertido en una prioridad.

- Paralelamente, muchos de los proyectos empiezan a guiarse básicamente por criterios de competitividad en relación con distintas clasificaciones consideradas prestigiosas (Brenner y Theodore 2002) y en "esta parafernalia se desarrollaron un sinnúmero de indicadores y modelos para evaluar el éxito de las ciudades" (Sabaté y Tironi 2008).

Así, algunos de estos planteamientos ponen en relación el éxito de las ciudades y el rango que ocupan en los distintos estudios. Derivado de ello, muchos ayuntamientos y autoridades han creado sociedades públicas o de capital mixto cuya función principal es que la ciudad adquiera el estatus de global o mundial. A continuación se presentan los ejemplos de Madrid, París, Sidney y São Paulo.

En el año 2007 en Madrid, bajo el gobierno del alcalde Gallardón, se creó la oficina "Madrid Global”, desaparecida después como consecuencia de la crisis. Los motivos para su implantación fueron que:

"[...] en este siglo XXI globalizado, una ciudad como Madrid, que aspira a la categoría de metrópoli mundial, debe tener una visión global e internacional tanto en su dirección como en su estrategia y gestión; por ello se apostó por ampliar las actuaciones tradicionales y complementarlas con nuevos enfoques, estrategias, programas y herramientas capaces de garantizar y asegurar un sólido posicionamiento internacional de la ciudad en las próximas décadas"3.
Posteriormente, con la alcaldesa Botella, se aprobó en 2011 el "Plan Estratégico de Posicionamiento Internacional de la Ciudad de Madrid 2012-2015", cuyo fin "no es otro que consolidar a Madrid como una ciudad de referencia a nivel internacional".

Con esta misma lógica, la Alcaldía de París se refería al estatus internacional que alcanza la ciudad en los distintos informes y estudios en un artículo publicado en su web institucional titulado "París, cuarta ciudad líder de la economía mundial"4:

\begin{abstract}
"PricewaterhouseCoopersc (PwC) ha analizado el desempeño cualitativo de las 27 ciudades más atractivas del mundo en 2012 [...] y en ella París muestra su alto nivel. Es la número 1 de las ciudades con mejor calidad de vida, por delante de las favoritas, Sidney y Hong Kong y reafirma así su condición de primera capital turística del mundo. París ocupa además el segundo lugar por detrás de Londres por su apertura internacional y poder económico, y sigue estando en el podio y se sitúa muy honorablemente la tercera de las ciudades más importantes por capital intelectual y fortaleza en la innovación".
\end{abstract}

Asimismo el Ayuntamiento de esta ciudad mantiene abierta la oficina "París Developpement" cuyo objetivo es "asegurar la promoción económica de París y su área metropolitana mediante actividades de búsqueda y captación de empresas internacionales" 5 .

Fuera del ámbito europeo también pueden encontrarse ejemplos de esta lógica. En Sidney se elaboró entre 2008 y 2013 un plan estratégico de carácter participativo, denominado "Sustainable Sydney 2030", cuyo objetivo es guiar la estrategia política de la ciudad en los próximos veinte años. La visión que se extrae de la participación de los ciudadanos es el deseo de una ciudad "verde, global y conectada" y entre los diversos objetivos del plan está el mantenimiento y consolidación de su carácter global:

\footnotetext{
"La Alcaldía de Sidney continua esforzándose para garantizar que los negocios locales se mantengan competitivos en el ámbito global. Para ello se está trabajando conjuntamente con el gobierno de Nueva Gales del Sur para atraer grandes eventos de negocios a la ciudad [...]. Entre los objetivos está consolidar la reputación de Sídney como el mejor centro de compras del país"6.
}

Las autoridades de esta ciudad promueven también la web "Global Sydney" cuyo objetivo fundamental es enfatizar su carácter global, como localización óptima para los negocios, el desarrollo de industrias creativas y como destino educativo de nivel internacional. Asimismo esta página se hace eco de distintas clasificaciones internacionales y del posicionamiento que alcanza la ciudad australiana:

\footnotetext{
"Sidney es considerada una ciudad mundial Alpha+ según la red GaWC de la Universidad de Loughborough. De acuerdo con este ranking la ciudad es una de las 10 ciudades mejor conectadas con Nueva York, Londres, Tokio, París y Hong Kong [...]. En 2013
} 
el Anholt-GfK City Brands Index señaló que Sidney era la segunda ciudad del mundo más atractiva en relación con su imagen y "marca de ciudad". Dentro del Global Financial Centres Index, Sidney mejoró su posición 8 puestos, desde el $15^{\circ}$ hasta el $5^{\circ}$ en la región de Asia-Pacífico [...]. El Global Power City Index la clasificó como una de las cuarenta ciudades más importantes del mundo [...] y además señaló que ocupaba el $9^{\circ}$ puesto en relación con el tamaño del mercado, su atractivo y su capital humano y el $11^{\circ} \mathrm{en}$ relación con la infraestructura e instalaciones para el visitante, los recursos culturales y su potencial para marcar modas"

Ejemplos de la utilización de los rangos proporcionados en los distintos listados urbanos para promoción y como forma de justificación de un tipo de práctica política se pueden encontrar también en grandes urbes de economías emergentes. En la web del Ayuntamiento de São Paulo (Brasil) aparece la siguiente reseña:

"São Paulo fue elegida por la consultora británica FDI Intelligence (Financial Times) la segunda ciudad más favorable para invertir en América, solo por detrás de Nueva York, superando a Toronto, Montreal, Vancouver y Houston [...]. A pesar de haber quedado por detrás de Nueva York en la clasificación general, la capital del Estado, que atrajo el 1,19\% de la Inversión Extranjera Directa (IED) el año pasado, fue la ciudad con el mejor potencial económico entre tres continentes y la mejor de América para recibir inversiones [...] Un estudio realizado por The Economist Intelligence Unit, (The Economist), publicado en junio, señaló que São Paulo mejorará su potencial competitivo en el mundo en los próximos 12 años [...]".

Como otras urbes que aspiran a ser globales, se creó en 2013 la agencia "São Paulo Negócios" adscrita al Departamento de Finanzas y Desarrollo Económico. Esta empresa pública es responsable de atraer inversiones y tiene entre sus objetivos: mejorar el ambiente de negocios en la ciudad, identificar y articular las oportunidades de inversión en sectores económicos definidos como estratégicos por el Poder Ejecutivo Municipal, mejorar la imagen de la ciudad en Brasil y en el extranjero, como polo para hacer negocios, y ayudar en la propuesta y ejecución de las medidas con el fin de optimizar el ambiente económico ${ }^{9}$.

En los casos propuestos, las posiciones alcanzadas en las distintas clasificaciones son utilizadas para la promoción de las ciudades (Ashworth y Voogd 1990), aunque las estrategias para ello puedan ser diversas. Precisamente existe cierta diferencia entre los objetivos que se proponen en las distintas ciudades y en los mecanismos de diseño de las políticas. En el caso de Sidney, su imagen como "ciudad global" se asume como algo deseado por los ciudadanos donde las componentes ambientales y la calidad de vida también se reflejan en la planificación; parece así que la "comercialización" de Sidney usando los distintos listados se hace a través de una estrategia botton-up, donde los ciudadanos participan de las decisiones. En principio se trata de planteamientos ligados a los principios de responsabilidad compartida y colaboración propuestos en el Documento Agenda $21^{10}$, No obstante algunos autores interpretan este hecho como una metamorfosis desde planteamientos neoliberales rígidos hacia otros donde, de manera cosmética, se contemplan también cuestiones de equidad social y calidad de vida (Peck y Tickell 2002; Graefe 2005), aspecto que igualmente puede ponerse en relación con el concepto de soft factors (Florida 2006; Musterd et al. 2007). Para otros es necesario incidir en la naturaleza biopolítica de las normas regulatorias de los procesos neoliberales, que se mimetizan, hibridan y adaptan a las contingencias locales (Ong 1996; Brenner, Peck y Theodore 2010).

En los casos de Madrid, São Paulo y París se desvela también un discurso que estresa la competitividad, pero primando un planteamiento ideado desde "arriba" (top-down) y no tanto meditado por la ciudadanía. De igual manera, parece claro que en estos ejemplos los gobiernos locales elijen para exaltar la globalidad de las ciudades aquellas clasificaciones que son más favorables, mientras que puede que se ignoren otros no tan positivos, olvidando que esta práctica puede utilizarse constructivamente para mejorar o para idear una estrategia más acorde con las necesidades (Tremblay et al. 2008). En cualquier caso se trata de una narrativa que enfatiza la ciudad como algo global, materializada a través de las prácticas de consultores a los que se les atribuye un poder, ante todo científico (McCann 2011). Se insiste además en las comparaciones entre sitios, lo que en algunos casos impulsa y favorece que los procesos sean realizados de la misma manera en distintas localizaciones, constituyendo así espacios de competición y emulación (Larner y Le Heron 2004).

Por tanto, los cuatro ejemplos aquí señalados pueden reconocerse dentro de las prácticas actuales de políticas rápidas o móviles (fast policy o mobilizing policies) ligadas a los actuales procesos neoliberales. En este caso concreto se trata de una serie de ideas "tecnocráticas" que impulsan modelos de planificación urbana que están circulando con una velocidad creciente, favorecidas por las nuevas redes de comunicaciones y también por los actores transnacionales, móviles, que trabajan en red. Todo ello, a nuestro juicio, parece indicar que se ha producido una desconexión entre el valor científico de las jerarquías de ciudades mundiales y la interpretación que se hace de ellas. En este sentido consideramos que la formulación actual de numerosos listados de ciudades puede, en ocasiones, resultar banal y carecer de significado geográfico. Los autores más críticos respecto a este tipo de prácticas sostienen que deben ser entendidas como ejemplos de las relaciones de poder, reflejo de los intereses dominantes, estando social e institucionalmente construidas, ya que se 
validan determinadas propuestas e ignoran otras. Se trataría de prácticas construidas ideológicamente, que a su vez tienen canales de comunicación propia y que consolidan y facilitan la convergencia económica necesaria para el libre-mercado (Mirowski y Plehwe 2009; Peck y Theodore 2010).

\section{Conclusiones: HACIA UNA VALORACIÓN DE LAS CLASIFICACIONES DE CIUDADES DESDE LA PERSPECTIVA TERRITORIAL}

Este trabajo ha mostrado cómo el concepto de ciudad global abrió una línea de investigación con una amplia trayectoria en ciencias sociales que recientemente ha sido enriquecida con nuevas variables e indicadores en referencia a una sociedad de servicios, con un creciente peso de las actividades culturales, creativas y de ocio-consumo. Paralelamente, este concepto ha sido ampliamente adoptado en el quehacer político y de planificación en relación con prácticas neoliberales que buscan la promoción económica de ciudades y territorios. En relación con las ideas anteriores, se ha observado como la elaboración de clasificaciones de ciudades ha trascendido la esfera de lo académico y que algunos investigadores han pasado a formar parte de esa élite especializada, esa "consultocracia" de asesores internacionales, freelances, organizadores de conferencias y personas dedicadas al marketing y a las relaciones publicas cuyas ideas son movilizadas internacionalmente a través de las redes de actores (Osborne 2004), y donde los medios de comunicación juegan un papel importante al hacerse eco y registrar los numerosos estudios que se realizan. Otra de las circunstancias que debe también considerarse es que el enfoque claramente economicista que tomaron desde el último cuarto del siglo XX los estudios sobre ciudades mundiales ${ }^{11}$, no revisado hasta fechas recientes (Parnreiter 2013), puede haber favorecido la adopción de parte de las ideas por tecnócratas, planificadores y consultores. En este sentido cabe decir que propuestas más integrales como la de Friedmann (1986) o con metodologías diferentes (RECLUS-DATAR 1989) no tuvieron el mismo eco.

Todo ello, a nuestro juicio ha vaciado de contenido geográfico el término ciudad global para ser simplemente una posición en un listado, al que se le concede el poder de dotar de "prestigio mundial" al tiempo que se justifica cierto tipo de actuaciones. Estas están socialmente producidas y conformadas por formas de conocimiento técnico, que informan, asesoran y diseñan cómo gobernar la ciudad. Sin embargo, los resultados de las investigaciones, con una trayectoria de más de un siglo, y la relevancia que ha adquirido el concepto de "ciudad global" insisten en su validez para entender determinados procesos que se desarrollan en la escala mundo. Por tanto, a la hora de valorar los listados de ciudades creemos necesario rescatar el marco interpretativo proveniente funda- mentalmente de la tradición sobre estudios urbanos iniciada por geógrafos anglosajones en los años 60, ya que, sin este las formulaciones aparecen totalmente descontextualizadas, lo que facilita una apropiación aprovechada por parte de determinados discursos.

1.- En primer lugar, los listados urbanos pueden ayudar a comprender el territorio, al identificar los centros donde se concentra toda aquella movilidad relacionada con la globalización y pueden ser considerados herramientas explicativas, especialmente en sus dimensiones económica y cultural.

Puede decirse, por tanto, que la determinación de las ciudades cuyo ámbito de influencia es de orden planetario y la formulación de un modelo que refleje un sistema de ciudades de alcance mundial proporciona evidencias relevantes de cómo se organiza el mundo, especialmente en términos de concentración de poder y si se analiza diacrónicamente, de las posibles reconfiguraciones. ¿Cómo si no sería posible analizar la emergencia del eje económico en la región de Asia-Pacífico y valorar el protagonismo que han tenido en todo ello sus ciudades, por ejemplo Beijing, Hong Kong, Shanghai o Singapur? Sin duda que muchos de estos aspectos pueden observarse utilizando otras referencias que no tienen como foco de interés el hecho urbano, pero a nuestro juicio, las evidencias adquieren expresividad científica y relevancia si se considera a las ciudades en su dimensión de centros de poder y conmutadores de movilidad (Castells 1989).

Consecuentemente, el concepto de ciudad global puede considerarse, además de una realidad geográfica, una herramienta metodológica cuya definición debe ser inclusiva, en tanto que la globalización afecta a gran parte de las ciudades, que se adaptan y transforman en este contexto. De esta manera, si se analiza la evolución del concepto y el debate sobre el término, puede observarse que más que restringirse, se ha ido enriqueciendo con propuestas en varios sentidos:

(i) al considerar que una parte de las grandes ciudades del mundo y aquellas que juegan roles relevantes en sus contextos regionales y nacionales pueden adquirir ciertos niveles de globalidad (Marcuse y Kempen 2000), proyectando así sus áreas de influencia mucho más allá de sus hinterland tradicionales. Esto mismo, no obstante, no presupone que todas las ciudades puedan llegar a tener funciones de orden global, ya que depende de una evolución histórica propicia que le haya permitido acumular funciones y de las características del territorio en que operan" (Smith y Timberlake 1995).

(ii) en la tipología de actividades que determinan el estatus de ciudad mundial, al introducir por ejemplo las actividades de innovación, culturales y creativas, enriqueciendo los análisis con perspectivas menos economicistas. 
2.- La idea de jerarquía urbana adquiere una mayor definición conceptual si va unido a la formulación de mallas o sistemas de ciudades, que permitan apreciar el papel que pueden jugar distintos núcleos tanto en el concierto mundial como dentro de los grupos o rangos en que se integran según su importancia. Esta apreciación parece ser obviada en la interpretación reciente de algunas propuestas. Es así como a la identificación de las principales ciudades del mundo deben unirse, necesariamente, el significado que adquieren según su rango y función en las dinámicas globales. En esta línea interpretativa Krätke (2004) insiste en que la ciudad global no debe solo interesar por ser una categoría de clasificación en el marco de una jerarquía, sino, más bien, un concepto para comprender el papel de las ciudades en el proceso de globalización.

3.- Se hace necesaria también una importante reflexión sobre los indicadores que se utilizan y su tratamiento matemático, ya que "no importa lo sofisticados que sean los datos empleados si solo sirven para establecer una jerarquía y no las relaciones que se establecen entre los distintos lugares" (Meyer 1998). Así, pese al importante ejercicio epistemológico realizado a la hora de identificar dimensiones e indicadores, lo que ha enriquecido de forma notable el cuerpo teórico, continúa siendo imprescindible una propuesta de indicadores altamente relevantes, que sean reflejo de especializaciones funcionales y pongan de manifiesto el carácter multidimensional de la globalización.

Se ha visto como algunas de las clasificaciones de ciudades analizadas, cuyos resultados proceden de cálculos complejos, no proporcionan resultados de mayor significado y relevancia que otros donde los indicadores empleados son menos numerosos pero cuya elección deriva de una cuidadosa justificación metodológica (Ej. GaWC). Cabe recordar que aquellos indicadores basados en la conectividad proveen de resultados especialmente significativos no solo al identificar las ciudades más importantes a escala global, sino también al determinar sus relaciones y el rol que desempeñan. En este sentido, casi todas las propuestas recientes parecen olvidar indicadores de relación y movilidad. Conviene recordar que una de las bases teóricas más exitosas sobre el concepto de ciudad mundial considera que las ciudades en el contexto de globalización son más bien producidas por los flujos entre estas que por lo fijado dentro de ellas (Castells 1989; Allen 1999; Derudder et al. 2003).
4.- Consideramos que la caracterización de una ciudad en la escala mundo debe abrir, necesariamente, las puertas al entendimiento de las dinámicas socioeconómicas que suceden en el ámbito regional y en el espacio interno de la ciudad. Se ha visto cómo las interpretaciones de corte neoliberal obvian que se trata de un proceso histórico y olvidan la variedad de dinámicas particulares que conducen el crecimiento de las regiones y de las ciudades, al tiempo que políticos y planificadores han dado demasiada importancia al rango o escalafón alcanzado en vez de desarrollar un detallado conocimiento de los nichos de especialización y de las particularidades (Cortright y Mayer 2004). También sucede que el desarrollo de acciones de planificación para conseguir un determinado rango genera dinámicas internas en la ciudad no siempre positivas y que pueden conducir a una mayor desigualdad socioeconómica y a la fragmentación espacial, tal como advirtieron en su día Friedmann (tesis de la polarización y del coste social, 1986) y Sassen (1991 y 2001).

5.- Resulta importante tener en cuenta que los ránquines no tienen por qué ser contemplados como "un juego competitivo de suma cero" (unas ciudades ganan porque otras pierden) (Tremblay et al. 2008) y que la comparación entre ciudades con características muy diferentes llama a equívocos, ya que a veces no ahondan en los problemas y circunstancias particulares.

En síntesis, creemos que se hace imprescindible revisar el significado interesado y parcial, encaminado a un fin comercial, publicitario o político, que se ha dado a los recientes listados de ciudades. Estos se han convertido en una herramienta más al servicio de las prácticas neoliberales $\mathrm{y}$, aunque algunos empiezan a incluir indicadores en relación con el medio ambiente y la calidad de vida, para determinados autores el objetivo en sí mismo no es alcanzar mayores estándares que repercutan en la ciudadanía, sino más bien proyectar internacionalmente a las ciudades (Peck y Tickell 2002; Graefe 2005).

\section{Agradecimientos}

Este trabajo ha sido realizado dentro del Plan Nacional de Innovación e Investigación 2013-2016. Ref. proyecto: CSO2016-75722-R (CITYTUR). Secretaría de Estado de Investigación, Desarrollo e Innovación.

\section{NOTAS}

$1 \quad$ La publicación de clasificaciones o listados de lugares o de ciudades por parte de organismos extra-académicos no es nueva, pero si la intensidad con que aparecen. Por ejemplo, desde 1981 se publica el Places Rated Almanac, que proporciona una jerarquía de ciudades y comunidades urbanas en relación con la calidad de vida. os listados de ciudades analizados han sido seleccionados en función de la relevancia que estos adquieren en las búsquedas en Internet, además de por la importancia y prestigio que tienen los organismos que los elaboran. munimadrid/es/Inicio/Actualidad/Noticias/Madrid-Glo- 
bal-la-nueva-estrategia-internacional-del-Gobierno-deGallardon?vgnextfmt=default\&vgnextoid=f3021c2cd5e3 3110VgnVCM1000000b205a0aRCRD\&vgnextchannel= a12149fa40ec9410VgnVCM100000171f5a0aRCRD

4 http://www.paris.fr/professionnels

5 http://www.investinparis.com/qui-sommes-nous

6 http://www.cityofsydney.nsw.gov.au/vision/ towards-2030/business-and-economy http://www.cityofsydney.nsw.gov.au/learn/research- and-statistics/the-city-at-a-glance/global-sydney/ourglobal-city

8 http://capital.sp.gov.br/noticia/sao-paulo-recebe-premio-de-2a-melhor-cidade-para

9 http://www.spnegocios.com

10 Capítulo 28. Agenda 21. Conferencia de Naciones Unidas sobre Medio Ambiente. Río de Janeiro, 1992.

11 A partir de las propuestas de Hymer (1972) y Cohen (1981).

\section{RefERencias Bibliográficas}

Alderson, A.S. y Beckfield, J. 2004. "Power and Position in the World City System". American Journal of Sociology, 109(4): 811-851. http://dx.doi.org/10.1086/378930

Allen, J. 1999. "Cities of power and influence: settled formations". Pp. 181-228 en Unsettling Cities. Londres: Routledge.

Amin, A. y Thrift, N. 2007. "Cultural-economy and cities". Progress in Human Geography, 31(2): 143-161. http:// dx.doi.org/10.1177/0309132507075361

Ashworth G. y Voogd, H. 1990. Selling the city. Londres: Belhaven.

Beaverstock J., Smith R. y Taylor P. 1999. "A roster of world cities". Cities, 16 (6): 445-58. http://dx.doi.org/10.1016/ S0264-2751(99)00042-6

Brenner, N. 1998. "Global cities, glocal states". Rev. of International Political Economy, 5(1): 1-37. http://dx.doi. org/10.1080/096922998347633

Brenner, N. y Theodore, N. 2002. Spaces of Neoliberalism: Urban Reestructuring. Oxford: Blackwell.

Brenner, N., Peck, J. y Theodore, N. 2010. "Variegated neoliberalization: geographies, modalities, pathways". Global networks, 10.2: 182-222. http://dx.doi.org/10.1111/ j.1471-0374.2009.00277.x

Bretagnolle, A., Pumain, D. y Vacchiani-Marcuzzo C. 2007. "Les formes des systèmes de villes dans le monde". Données urbaines, 5: 301-314.

Benton-Short, L., Price, M.D., y Friedman, S. 2005. "Globalization from below: the ranking of global immigrant cities". International Journal of Urban and Regional Research, 29(4): 945959. http://dx.doi.org/10.1111/j.1468-2427.2005.00630.x

Canosa, E. y García, A. 2012. "La construcción de la marca Madrid". Cuadernos Geográficos, 51, 12. http://revistaseug.ugr.es/index.php/cuadgeo/article/view/239/344

Castells, M. 1989. The Informational City. Oxford: Blackwell.

Cohen, R.J. 1981. "The new international division of labour, multinational corporations and urban hierarchy". Pp. 287- 315 en Urbanisation and Urban Planning in Capitalist Society. Londres: Methuen.

Córdoba, A. y Gago, C. 2012. "Globalización, movilidad y análisis de conectividad aérea: una herramienta para la práctica interdisciplinar". Revista de Antropología Social, 21: 117-146. http://dx.doi.org/10.5209/rev_ RASO.2012.v21.40052

Cortright, J. y Mayer, H. 2004. "Increasingly Rank: the Use and Misuse of Rankings in Economic Development". Economic Development Quarterly, 18(1): 34-39. http:// dx.doi.org/10.1177/0891242403260285

Currid, E. 2006. "New York as a global creative hub". Economic Development Quarterly, 20(4): 330-350. http://dx.doi. org/10.1177/0891242406292708

Derudder, B. 2006. "On conceptual confusion in empirical analyses of a transnational urban network". Urban Studies, 43(11): 2027-2046. http://dx.doi. org/10.1080/00420980600897842
Derudder, B. et al. 2003. "Hierarchical tendencies and regional patterns in the World city network". Regional Studies, 37(9): 875-886. http://dx.doi. org/10.1080/0034340032000143887

Derudder, B. y Taylor, P. 2005. "Cliquishness of World Cities". Global Networks, 5(1): 71-91. http://dx.doi.org/10.1111/ j.1471-0374.2005.00108.x

Derudder, B. y Witlox, P. 2005. "Mapping world city networks through airline flows". Journal of Transport Geography, 16(5): 305-312. http://dx.doi.org/10.1016/j.jtrangeo.2007.12.005

Dollfus, O. 1990. "Le sistème Monde". L'Information Géographique, 54: 45-52.

Evans, G. 2009. "Creative Cities, Creative Spaces and Urban Policy". Urban Studies, 46(5-6): 1003-1040. http:// dx.doi.org/10.1177/0042098009103853

Florida, R. y Tingali, I. 2004. Europe in the Creative Age. Boston: Alfred P. Sloan Foundation.

Florida, R. 2002. The Rise of the Creative Class. Nueva York: Basic Books.

Florida, R. 2005. Cities and the Creative Class. Londres: Psychology Press.

Florida, R. 2006. The flight of the creative class. New York: Harper Business.

Friedmann, J. 1986. "The world city hypothesis". Development and Change, 17: 69-83. http://dx.doi. org/10.1111/j.1467-7660.1986.tb00231.x

Fuentes, L. 2011. "Competitividad urbana en el contexto latinoamericano. El caso de Santiago de Chile". Revista de Geografía Norte Grande, 48: 81-106. http://dx.doi. org/10.4067/S0718-34022011000100006

Geddes, P. 1915. Cities in Evolution. Londres: Williams and Norgate.

Giddens, A. 2007. Sociología. Madrid: Alianza Editorial.

Gago, C. 2002. Región, Política y Transporte aéreo. Tesis Doctoral. Madrid: UCM.

Giffinger, R. et al. 2010. "The role of rankings in growing city competition". Urban Research \& Practice, 3(3): 299312. http://dx.doi.org/10.1080/17535069.2010.524420

Graefe, P. 2005. "Roll-out Neoliberalism and the Social Economy". Paper prepared for the Annual Meeting of the Canadian Political Science Association, University of Western Ontario. https://www.cpsa-acsp.ca/papers-2005/Graefe.pdf

Hall, P. 1966. The World Cities. Londres: World University Library.

Halbert L. 2004. Densité, desserrement, polycentrisme et transformation économique des aires métropolitaines. PhD thesis, Université Paris-I.

Halbert L. 2008. "Examining the Mega-City-Region Hypothesis: Evidence from the Paris City-Region/Bassin parisien". Regional Studies, Vol. 42 (8): 1147-1160. http://dx.doi.org/10.1080/00343400701861328 
Harvey D. 1989. "From Managerialism to Entrepreneurialism: The Transformation in Urban Governance in Late Capitalism". Geografiska Annaler, Series B, Human Geography 71(1): 3-17. http://dx.doi.org/10.2307/490503

Hymer, S. 1972. "The multinational corporation and the law of uneven development". Pp. 113-140 en Economics and World Order. Londres: Macmillan.

Jessop, B. y Sum, N. 2000. "An intrerpreneurial city in action: Hong Kong's emerging strategies". Urban Studies, 37(12): 2287-2313. http://dx.doi. org/10.1080/00420980020002814

Jonhson, R.J. 1994. "World cities in a world system". International Journal of Urban and Regional Research, 18(1): 150-152.

King, A.D. 1995. Re-presenting the city: ethnicity, capital and culture in the twenty-first century metropolis. Basingstoke: Macmillan.

Krätke, S. 2004. "City of Talents? Berlin's Regional Economy". International Journal of Urban and Regional Research, 28 (3): 511-529. http://dx.doi.org/10.1111/j.0309 1317.2004.00533.x

Larner, W. y Le Heron, R. 2004. "Global benchmarking: Participating "at a distance" in the globalising economy". Pp. 212-212 en Global governmentality: Governing Intern. Spaces. Londres: Routledge.

Larner, W. y Laurie, N. 2010. "Travelling technocrats, embodied knowledges: globalising privatisation in telecoms and water", Geoforum, 41(2): 218-226. http://dx.doi. org/10.1016/j.geoforum.2009.11.005

Lash, S. y Urry, J. 1994. Economies of Signs and Space. Londres: Sage.

McCann, E.J. 2011. "Urban policy mobilities and global circuits of knowledge: Toward a research agenda". Annals of the Association of American Geographers, 101(1): 107130. http://dx.doi.org/10.1080/00045608.2010.520219

Mansvelt, J. 2008. "Geographies of consumption". Progress in Human Geography, 32(1): 105-117. http://dx.doi. org/10.1191/0309132504ph486pr

Marcuse, P. y Kempen, R. 2000. Globalizing Cities: A New Spatial Order? Oxford: Blackwell.

Markusen, A. y Schrock, G. 2006. "The distinctive city". Urban Studies, 43(8): 1301-1323. http://dx.doi. org/10.1080/00420980600776392

Mayor of London. 2012. World Cities Culture Report, 2012. Londres.

Méndez, R. y Sánchez, S. 2011. "Spanish cities in the knowledge economy". European Urban and Regional Studies, 18(2): 136-155. http://dx.doi. org/10.1177/0969776410381039

Meyer, D. 1998. "World cities as international financial centres". Pp. 410-432 In Globalization and the World of Large Cities. Tokyo: ONU.

Mihye, C. 2010. "Envisioning Seoul as a World City". Asian Studies Review, 34: 329-347. http://dx.doi.org/10.108 0/10357823.2010.508101

Miles, S. 2012. "The neoliberal city and the pro-active complicity of the citizen consumer". Journal of Consumer Culture, 12(2): 216-230. http://dx.doi. org/10.1177/1469540512446881

Mirowski P. y Plehwe D. (Eds.) 2009. The Road from Mont Pelerin: The Making of the Neoliberal Thought Collective. Cambridge, MA: Harvard University Press.

Molotch, H. 1996. "LA as design product: how art Works in a regional economy", Pp. 225- 275 en The City: Los Angeles and urban theory at the end of twentieth Century. Berkeley: Univ. de California.
Musterd, S. et al. 2007. Accommodating creative knowledge. Amsterdam: Amsterdam University.

Olds, K. y Yeung, H.W. 2004. "Pahtways to global city formation". Review of International Political Economy, 11(3): 489521. http://dx.doi.org/10.1080/0969229042000252873

Ong, A. 2006. Neoliberalism as exception: Mutations in citizenship and sovereignty. Durham: Duke University Press.

Osborne, T. 2004. "On mediators: Intellectuals and the ideas trade in the knowledge society". Economy and Society, 3(4): 430-47. http://dx.doi. org/10.1080/0308514042000285224

Parnreiter, C. 2013. "The global city tradition". Pp. 15-32 en Global City Challenges. Palgrave: Macmillan.

Peck, J. 2002. "Political Economies of Scale: Fast Policy, Interscalar Relations, and Neoliberal Workfare". Economic geography, 78(3): 331-360. http://dx.doi. org/10.1111/j.1944-8287.2002.tb00190.x

Peck, J. 2009. "The cult of urban creativity". Pp. 159-176 en Leviathan Undone? Towards a Political Economy of Scale. Vancouver: University of British Columbia Press.

Peck, J. y Tickell, A. 2002. "Neoliberalizing Space". Antipode, 34(3): 380-404. http://dx.doi.org/10.1111/14678330.00247

Peck J. y Theodore N. 2010. "Mobilizing policy: Models, methods, and mutations". Geoforum 41: 169-174. http:// dx.doi.org/10.1016/j.geoforum.2010.01.002

Peck, J. y Theodore, N. 2015. Fast Policy: Experimental Statecraft at the Thresholds of Neoliberalism. Minneapolis: Minnesota Univ. Press. On line: https://muse.jhu.edu/ book/40056

Porter, M.E. 2000. "Location, competition, and economic development: local clusters in a global economy". Economic Development Quarterly, 14: 15-34. http://dx.doi. org//10.1177/089124240001400105

Pratt, A.C. 2011. "The cultural economy and the global city". Pp. 265-274 en International Handbook of Globalization and World Cities, edited by. P. Taylor et al. Cheltenham: Edward Elgar.

Ritzer, G. 1993. The McDonaldization of Society. Los Ángeles: Pine Forest.

Rose, N. y Miller, P. 1992. "Political power beyond the state: Problematics of government". British Journal of Sociology, 43 (2): 172-205. http://dx.doi.org/10.2307/591464

Rozenblat, C. y Pumain, D. 2005. "Firm linkages, innovation and the evolution of urban systems". Pp. 130-156 in Cities in Globalization: Practices, Policies, Theories. Londres: Routledge.

Sabaté, J. y Tironi, M. 2008. "Rankings, creatividad y urbanismo". Eure, XXXIV, 102: 5-23. http://dx.doi.org/10.4067/ S0250-71612008000200001

Sánchez Moral, S. 2011. "Contribución de los servicios al desarrollo urbano en el contexto de la Globalización y la Sociedad del Conocimiento". Pp. 611-658 en V Congreso de Geografía de los Servicios. Cáceres: AGE.

Sassen S. 1994. Cities in a World Economy. Pine Forge: Thousand Oaks.

Sassen, S. 1991, 2001. The Global City. Princeton: University Press.

Scott, A. 2000. The Cultural Economy of Cities. Londres: Sage.

Scott, A. 2011. Global City-Regions: Trends, Theory, Policy. Nueva York: Oxford University Press.

Scott, A. 2007. "Capitalism and urbanization in a new key? The cognitive-cultural dimension". Tabula Rasa, (6), 195-217. 
Skorska, M. y Kloosterman, R. 2012. "Performing on the global stage: exploring the relationship between finance and arts in global cities". GaWC Research Bulletin, 412.

Smith, D.A. y Timberlake, M. 1995. "Conceptualising and Mapping the Structure of the World System's City System". Urban Studies, 32: 287-302. http://dx.doi. org/10.1080/00420989550013086

Smith and Timberlake, 2002. "Hierarchies of dominance among world cities". Pp. 117-141 in Global Networks, Linked Cities. Londres: Routledge.

Smith, R.G. 2003. "World city topologies". Progress in Human Geography. 27(5) 561-582. http://dx.doi. org/10.1191/0309132503ph447oa

Soja E. y Scott A. 1986. "Los Angeles: capital of the late twentieth century". Environment and Planning D, 4(3): 249254. http://dx.doi.org/10.1068/d040249

Swyngedouw, E. et al. 2002. "Neoliberal Urbanization in Europe: Large-Scale Urban Development Projects and the New Urban Policy". Antipode, 34(3): 542-547. http://dx.doi.org/10.1111/1467-8330.00254

Taylor, P. 2001. "Urban Hinterworlds: Geographies of Corporate Service Provision under Conditions of Contemporary Globalization". Geography, 86(1): 51-60.

Taylor, P. 2002. Global Cities. Londres: Routledge.

Taylor, P. 2004. World City Network. Global Urban Analysis. Nueva York: Routledge.
Taylor, P., Beaverstock J. y Derudder, B. 2013. Global cities. Critical Concepts. Londres: Routledge.

Temblay, R. et al. 2008. "Places Ratings, Shifting Neoliberalism and the Quality life in Communities", Interventions Économiques, 37. http://interventionseconomiques. revues.org/495

Thrift, N. 2000. "Non-representational theory". The Dictionary of Human Geography, edited by Johnston R.J. etal. Oxford: Blackwell. https://books.google.es/books?hl=es\&lr=\&i $\mathrm{d}=5 \mathrm{gCH}$ ckKszz0C\&oi=fnd\&pg $=$ PA1974\&dq=nor+rep resentational+theory+human+geography+dictionary\& ots=fuY-n jPQq\&sig=0rZ7 2SBhuwVaZRZDHMkvC $\mathrm{TAw} \# \mathrm{v}=$ onepage $\& \mathrm{q}=$ nor $\% 20$ representational $\% 20$ theory $\% 20$ human $\% 20$ geography $\% 20$ dictionary $\& \mathrm{f}=$ false

Thrift, N. 2007. Non-representational Theory. Londres: Routledge.

Townsend, A. 2001. "Network Cities and the Global Structure of the Internet". American Behavioral Scientist, 44(10): 1697-1716. http://dx.doi. org/10.1177/00027640121957998

Turok, I. 2004. "Cities, Regions and Competitiveness". Regional Studies, 38(9): 1069-1083. http://dx.doi. org/10.1080/0034340042000292647

Urry, J. 2002. The Tourist Gaze. London: Sage.

Yeoh, B. 2005. "The global cultural city? Spatial imagineering and politics in the (multi)cultural marketplaces of South-east Asia". Urban Studies, 42: 945-958. http:// dx.doi.org/10.1080/00420980500107201

CÁNDIDA GAGO GARCíA. Profesora Titular de Análisis Geográfico Regional en la Universidad Complutense. Su interés científico se centra en las repercusiones territoriales de la Globalización, especialmente su incidencia en la configuración de regiones en la escala mundo y el papel que en esta juegan los núcleos urbanos. Autora de numerosos artículos nacionales e internacionales en revistas de temática relacionada con la Geografía y también la Ciencia Social en General.

JUAN CÓRDOBA ORDÓÑEZ. Catedrático de Análisis Geográfico Regional en la Universidad Complutense y director del grupo de investigación validado por la Comunidad de Madrid "Territorio, Desarrollo y Cultura. Teoría y prácticas en la dialéctica Norte-Sur" (Ref. UCM-940614). Su línea de investigación preferente se centra en el análisis de procesos de transformación cultural y territorial relacionados con la globalización, con énfasis particular en los efectos de las nuevas movilidades y del turismo en territorios y sociedades. Autor de artículos sobre la vertebración de las regiones en la escala global, el significado y relevancia de las ciudades mundiales y el reciente papel del turismo como elemento de re-territorialización. Director de cinco proyectos de investigación consecutivos dentro del Plan Nacional de Investigación.

ROBERTO DÍEZ PISONERO. Doctor en Geografía por la Universidad Complutense (Doctorado Europeo) con una tesis titulada "El aeropuerto y la Ciudad en los escenarios de la Globalización". Premio Extraordinario fin de Carrera en la Licenciatura de Geografía y Primera Mención Especial en los Premios Nacionales a la Excelencia en el Rendimiento Académico Universitario. Ha realizado estancias de investigación predoctorales en universidades norteamericanas, europeas y latinoamericanas. Investigador titular en el ILS- Research Institute (Dortmund, Alemania) en 2016 